\title{
PEMANFAATAN ETHNOSCIENCE BERORIENTASI PEMBELAJARAN TEKNOLOGI TEPAT GUNA PADA KELOMPOK GURU GUGUS KARANGREJO GUNA MENYIAPKAN SISWA KOMPETEN DI ERA REVOLUSI INDUSTRI 4.0
}

\section{UTILIZATION OF ETHNOSCIENCE LEARNING APPROPRIATE TECHNOLOGY IN THE TEACHER GROUP OF KARANGREJO GUGUS TO PREPARE COMPETENT STUDENTS IN THE ERA OF INDUSTRIAL REVOLUTION 4.0}

\author{
Ahmad Rofi' ${ }^{\# 1}{ }^{1}$, Azamataufiq Budiprasojo ${ }^{\# 2}$, Risse Entikaria Rachmanita ${ }^{\# 2}$, Dafid Ari Prasetyo ${ }^{\# 2}$ \\ ${ }^{\#}$ Jurusan Teknik, Politeknik Negeri Jember \\ Jalan Mastrip Kotak Pos 164 Jember \\ ${ }^{1}$ rofiiapolije.ac.id \\ ªzamataufiq@polije.ac.id \\ ${ }^{2}$ risse_rachmanita@polije.ac.id \\ ${ }^{2}$ dafidepolije.ac.id
}

Abstrak

Salah satu upaya yang tengah dilakukan oleh pemerintah adalah dengan meningkatkan kompetensi guru dalam bidang pengajaran dan mengembangkan iklim keunggulan kompetitif serta terciptanya sumber daya manusia yang menguasai IPTEK adalah dengan memacu pendidikan yang berbasis teknologi dengan lingkungan sebagai sumber belajar. Kelompok Kerja Guru (KKG) Gugus Karangrejo Kecamatan Sumbersari yang merupakan kelompok diskusi guru pendidikan dasar se wilayah kerja unit Karangrejo Kecamatan Sumbersari. Berbasarkan analisis situasi dari wawancara dan observasi diperoleh permasalahan yang dialami mitra antara lain guru kurang memiliki pengetahuan dalam merencanakan dan mengekplorasi ide/ gagasan inovasinya dalam pembelajaran melalui kegiatan aktif serta dituangkan melalui alat pembelajaran berorientasi teknologi tepat guna, tenaga guru kurang menguasai keluasan materi dan perkembangan teknologi masa kini, terutama materi yang dapat dieksplorasi dalam alat pembelajaran, tidak adanya pelatihan khusus untuk melatih keterampilan dan kompetensi berbasis teknologi tepat guna melalui alat pembelajaran. Solusi yang dapat dilakukan adalah dengan memberikan pelatihan, pendampingan dan fasilitas pada mitra melalui tahapan survei, implementasi kegiatan hingga pelaksanaan evaluasi yang langsung berdampak pada mitra. Hasil diperoleh dari kegiatan pengabdian yaitu diperoleh banyak perubahan, mulai dari perubahan pemahaman dan pengetahuan tentang penerapan ethnoscience yang dapat diterapkan melalui penggunaan alat teknologi tepat guna. Alat ini dihasilkan oleh guru melalui pelatihan dan pendampingan oleh tim sebagai pemateri, pendamping dan penilai serta memberikan konfermasi mengenai metode dan proses kerja yang tepat sehingga dapat digunakan dalam pembelajaran secara efektif dan bermanfaat. Dari hasil wawancara dan observasi diperoleh bahwa penerapan ethnoscience dalam proses pembelajaran sangat bermanfaat dalam mengantarkan pemahaman siswa pada teknologi yang dilakukan secara langsung melalui alat teknologi tepat guna bahkan meningkatkan pemahaman dan pengetahuan mitra sehingga memberikan keyakinan untuk menerapkan lebih lanjut

Kata Kunci : Teknologi, Ethnoscience, Revolusi 4.0

Abstract

One of the efforts being made by the government is to improve teacher competence in the field of teaching and develop a climate of competitive advantage as well as the creation of human resources who master science and technology is to promote technology-based education with the environment as a learning resource. The Teachers Working Group (KKG) of the Karangrejo Cluster, Sumbersari District, which is a discussion group for basic education teachers in the Karangrejo unit of Sumbersari District. Based on the situation analysis from interviews and observations, it was found that the problems experienced by partners included teachers lacking knowledge in planning and exploring innovative ideas / ideas in learning through active activities and poured out through appropriate technology-oriented learning tools, teachers lacking mastery of material breadth and technological developments today, especially material that can be explored in learning tools, there is no special training to train appropriate technology-based skills and competencies through learning tools. The solution that can be done is by providing training, mentoring and facilities to partners through the survey stages, implementing activities to implementing evaluations that directly impact partners. The results obtained from the service activities were that there were many changes, starting from changes in understanding and knowledge of the application of ethnoscience that can be applied through the use of appropriate technology tools. This tool is produced by the teacher through training and mentoring by the team as a speaker, companion and assessor as well as providing conferences regarding appropriate work methods and processes so that they can be used in learning effectively and useful. From the results of interviews and observations, it was found that the application of ethnoscience in the learning process was very useful in delivering students' understanding of technology which was carried out directly through appropriate technology tools and even increased understanding and knowledge of partners so as to provide confidence to apply further

Keywords : Teknologi, Ethnoscience, Revolusi 4.0 


\section{PENDAHULUAN}

Perkembangan ilmu pengetahuan dan teknologi yang berkembang sangat pesat turut memberikan dampak pada keberlangsungan pendidikan, khususnya dalam menyiapkan dan memberikan bekal untuk menghadapi perkembangan global. Sebagaimana yang menjadi salah satu isu strategis bergesernya pembangunan global MDGs (Millennium Development Goals) menuju agenda pembangunan global baru yang dikenal sebagai SDGs (Sustainable Development Goals) atau Tujuan Pembangunan Berkelanjutan adalah jaminan kualitas pendidikan yang inklusif dan merata serta menguatkan masyarakat dalam pembangunan berkelanjutan terutama yang menjamin ketersediaan pendidikan yang menjamin kualitas hidup manusia (BPS, 2016). Salah satu upaya yang tengah dilakukan oleh pemerintah adalah dengan meningkatkan kompetensi guru dalam bidang pengajaran dan mengembangkan iklim keunggulan kompetitif serta terciptanya sumber daya manusia yang menguasai IPTEK sebagaimana yang tertera dalam RPJMN III tahun 2014-2019 (Kemdikbud,2015). Terlebih lagi dengan tantangan revolusi industry 4.0 yang menggabungkan tren teknologi otomatisasi dan teknologi cyber. Strategi yang dapat dikembangkan untuk menuju capaian tersebut adalah dengan menerapkan dan memanfaatkan ethnoscience yang berorientasi teknologi tepat guna yang dikemas melalui alat pembelajaran. Ethnoscience pada bahasan in berarti menerapkan science dengan basis budaya dan kondisi lingkungan.

Kelompok Kerja Guru (KKG) Gugus Karangrejo Kecamatan Sumbersari yang merupakan kelompok diskusi guru pendidikan dasar se wilayah kerja unit Karangrejo Kecamatan Sumbersari. Kelompok kerja guru tersebut berasal dari 7 satuan pendidikan dasar yang berada di kawasan kelurahan Karangrejo dan di bawah naungan unit Dinas Pendidikan Kabupaten Jember. Berdasarkan hasil observasi lapangan dan wawancara dengan mitra diperoleh informasi bahwa kendala terbesar yang belum terpecahkan oleh mereka adalah belum mampu menerapkan secara riil produk alat pembelajaran yang berbasis science. Kendala lain yang masih mendominasi adalah belum terpetakannya budaya dan lingkungan sebagai sumber belajar yang mendukung peningkatan kompetensi siswa.
Berdasarkan catatan Evaluasi Diri Sekolah (EDS) 2018/2019 yang dievaluasi setiap tahun sebagai rujukan sekolah dalam menentukan kebijakan sekolah satu tahun yang akan datang diperoleh data pada sebagai berikut.

\begin{tabular}{|c|c|}
\hline Komponen & Tahapan penilaian \\
\hline $\begin{array}{l}\text { Struktur dan kerangka } \\
\text { dasar kurikulum }\end{array}$ & $\begin{array}{l}\text { - } \\
\text { tahapan kelum mencakup } \\
\text { penggunaan alat peraga } \\
\text { inovatif dalam pembelajaran } \\
\text { - Belum mencakup } \\
\text { penerapan pembelajaran } \\
\text { berbasis budaya dan } \\
\text { lingkungan yang berorientasi } \\
\text { pada science }\end{array}$ \\
\hline $\begin{array}{l}\text { Pelaksanaan } \\
\text { pembelajaran }\end{array}$ & $\begin{array}{l}\text { - Belum melakukan } \\
\text { kegiatan pembelajaran berbasis } \\
\text { alat peraga } \\
\text { - Belum adanya } \\
\text { prestasi atau hasil karya } \\
\text { teknologi tepat guna }\end{array}$ \\
\hline $\begin{array}{l}\text { Kompetensi guru } \\
\text { (pengetahuan dan } \\
\text { keterampilan) }\end{array}$ & $\begin{array}{l}\text { - Belum memahami } \\
\text { secara konseptual dan tidak dapat } \\
\text { membuat serta menggunakan alat } \\
\text { peraga secara baik dalam } \\
\text { pembelajaran dan mengabaikan } \\
\text { lingkungan sebagai sumber } \\
\text { belajar. } \\
\text { - Belum adanya } \\
\text { pelatihan dan pendampingan } \\
\text { tentang penerapan teknologi } \\
\text { tepat guna dan sumber belajar } \\
\text { berbasis science }\end{array}$ \\
\hline
\end{tabular}

Dari observasi dan wawancara pada mitra ditemukan beberapa permasalahan, diantaranya;guru kurang memiliki pengetahuan dalam merencanakan dan mengekplorasi ide/ gagasan inovasinya dalam pembelajaran melalui kegiatan aktif serta dituangkan melalui alat pembelajaran berorientasi teknologi tepat guna, tenaga guru kurang menguasai keluasan materi dan perkembangan teknologi masa kini, terutama materi yang dapat dieksplorasi dalam alat pembelajaran, tidak adanya pelatihan khusus untuk melatih keterampilan dan kompetensi berbasis teknologi tepat guna melalui alat pembelajaran dan tuntutan secara umum dari stakeholder akan perlunya peningkatan kualitas pendidikan dan kesiapan siswa dalam menghadapi tantangan global dan revolusi industry 4.0 Berdasarkan analisis situasi dan data yang diperoleh dari mitra, maka diperlukan upaya untuk meningkatkan kompetensi guru dalam pemanfaatan ethnoscience untuk membuat alat pembelajaran berorientasi teknologi tepat guna denganmemperhatikan keadaan lingkungan dan budaya sekitar sebagai sumber belajar. 


\section{TARGET DAN LUARAN}

Target yang diusahakan pada kegiatan pengabdian masyarakat melalui pada mitra Kelompok Kerja Guru (KKG) Gugus Karangrejo adalah meningkatnya pengetahuan dan pemahaman guru dalam membuat dan melakukan inovasi pembelajaran melalui penerapan alat teknologi tepat guna berbasis ethnoscience dan meningkatnya minat guru dalam mengembangkan alat teknologi tepat guna berbasis ethnoscience dalam pembelajaran. Luaran yang diberikan pada program pengabdian kepada masyarakat antara lain; alat tepat guna berbasis ethnoscience, artikel pada jurnal pengabdian, video kegiatan, foto kegiatan, dan poster pengabdian. Luaran tambahan yang bisa diberikan adalah laporan penelitian tindakan kelas (PTK) yang dapat dilakukan oleh guru.

\section{METODE PELAKSANAAN}

Metode pelaksanaan program pengabdian masyarakat pada dilakukan melalui beberapa tahap, antara lain:

1) Tahap Survei

Kegiatan yang dilakukan antara lain mengidentifikasi dan pengumpulan data mitra, menentukan point permasalahan yang dialami mitra dengan didukung oleh data primer dari mitra. Pada tahap ini juga dilakukan analisis situasi lingkungan dengan mempertimbangkan keadaan lingkungan sekitar sebagai sumber belajar sehingga muncul ide bentuk alat teknologi tepat guna yang dibutuhkan dalam penerapannya melalui pembelajaran. Tahap selanjutnya adalah berdiskusi dengan mitra untuk menentukan metode yang digunakan dalam sosialisasi pada kelompok guru mengenai program pengabdian yang akan dilakukan. Selanjutnya memetakan masalah untuk dilakukan tindakan penyelesaian melalui program pelatihan dan pendampingan.

2) Tahap Implementasi

Kegiatan yang dilakukan antara lain menentukan metode pelatihan dan pendampingan tim kepada mitra. Pelatihan dan pendampingan yang dilakukan tim menyesuaikan dengan kondisi lingkungan masing-masing kelompok yang tergabung dalam kelompok kerja guru (KKG). Pada kegiatan pelatihan, tim memberikan pemahaman dan pengetahuan tentang penerapan alat teknologi tepat guna berbasis ethnoscience yang diterapkan dalam pembelajaran. Kegiatan pendampingan dilakukan setelah melakukan kegiatan pelatihan dengan memonitoring kegiatan yang dilakukan oleh mitra dalam menerapkan hasil pelatihan oleh tim.

3) Tahap Evaluasi

Kegiatan evaluasi merupakan kegiatan yang dilakukan untuk mengukur tingkat ketercapaian tujuan dan program pengabdian pada mitra. Pada tahap evaluasi, tim memonitoring dan mengobservasi secara langsung pada mitra tentang tingkat perubahan pemahaman dan pengetahuan setelah dilakukan tindakan oleh tim melalui program pengabdian.

Kegiatan evaluasi dilakukan dengan mengumpulkan komponen-komponen luaran yang dibutuhkan serta laporan akhir.

\section{HASIL DAN PEMBAHASAN}

Pelaksanaan kegiatan pengabdian kepada masyarakat di Rumah Industri Kue Balok Oma Jember dengan tahapan-tahapan yang dilakukan diperoleh hasil sebagai berikut:

1) Proses tahap survey

Pada tahapan survey terlebih dahulu dilakukan pengamatan dan wawancara secara langsung pada mitra untuk mengetahui permasalahan yang dihadapi oleh mitra serta mengumpulkan sumber data, baik data secara tertulis maupun lisan dari pengurus Kelompok Kerja Guru (KKG) Gugus Karangrejo. Hasil wawancara dan observasi yang didukung dengan data primer selanjutnya dilakukan analisis untuk ditentukan solusi dan point terpenting yang perlu ditangani secara serius dalam memecahkan permasalahan yang dihadapi. Hasil analisis data yang dihasilkan kemudian didiskusikan bersama dengan mitra. Selanjutnya dilakukan sosialisasi pelaksanaan kegiatan pelatihan oleh tim bersama mitra.

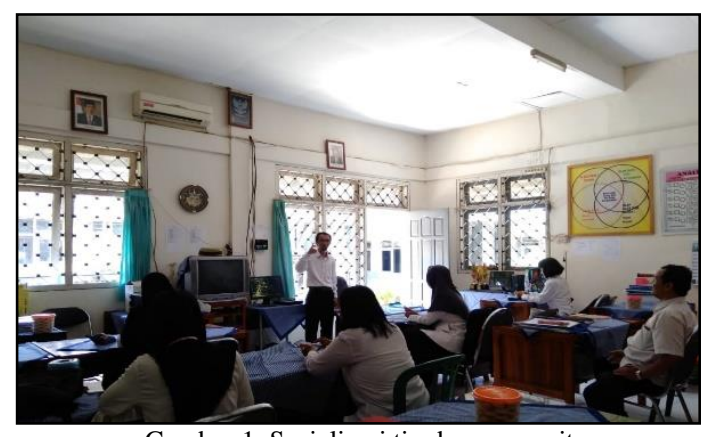

Gambar 1. Sosialisasi tim bersama mitra

Pada tahapan selanjutnya dilakukan diskusi secara berkala dengan mitra sebanyak 2 kali pertemuan untuk menyelesaikan desain dan metode pelatihan dan pendampingan melalui FGD yang difasilitasi oleh mitra. Pada kegiatan FGD bersama mitra disepakati metode pelatihan dan pendampingan 
pada mitra secara berkala dengan pemateri dari tim dan peserta dari mitra yang nerupakan Kelompok Kerja Guru (KKG) Gugus Karangrejo dengan melibatkan 7 sekolah pada satuan pendidikan KKG wilayah kerja Karangrejo. Peserta yang dilibatkan terdiri atas 5 guru pada setiap sekolah dan kepala sekolah.

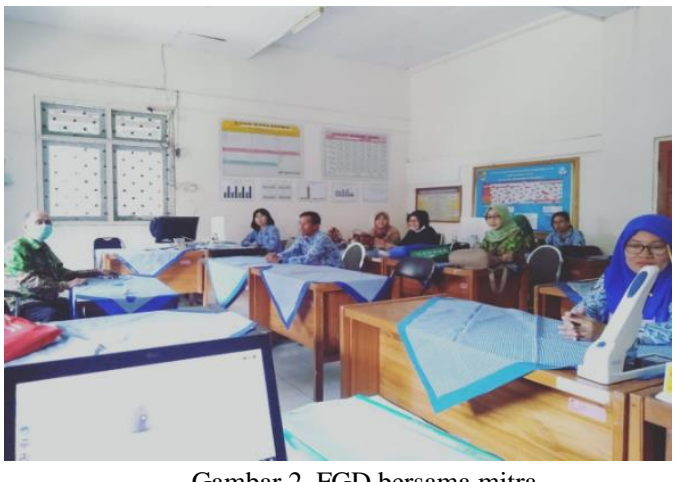

Pada kegiatan FGD juga dihasilkan metode pendampingan yang akan dilakukan oleh tim bersama mitra yang ditunjuk sebagai tim inti yang bertugas mensupervisi kegiatan dan evaluasi kegiatan yang dilakukan. Kegiatan pada sesi I berjalan dengan baik dan lancar. Peserta dengan antausias mendengarkan dan terjadi diskusi yang interaktif saat waktu diskusi bersama tim. Dengan memperhatikan proses pelatihan pada sesi I tampak bahwa peserta yang merupakan guru merasakan kurangnya pemahaman dan pengetahuan tentang materi yang diberikan sehingga memberikan danpak yang positif bagi tambahan informasi dan pengetahuan guru

2) Hasil pada tahapan implementasi

Setelah dilakukan kegiatan sosialisasi dan FGD bersama dengan mitra, maka selanjutnya dilakukan implementasi kegiatan berupa pelatihan dan pendampingan tim pada mitra. Kegiatan pelatihan terbagi menjadi 2 sesi dengan setiap sesi diberikan materi oleh tim pelaksana program pengabdian dari Politeknik Negeri Jember. Pembagian sesi dan jumlah peserta dilakukan untuk lebih mengefektifkan proses pelatihan sekaligus pendampingan langsung oleh tim bisa berjalan secara efektif.

a). Pelatihan dan pendampingan sesi I.

Kegiatan pelatihan dan pendampingan pada sesi I dihadiri oleh tim sebagai pemateri dan pendamping. Materi yang diberikan pada sesi I adalah konsep ethnoscience dalam implementasi teknologi tepat guna, konsep pembelajaran ethnoscience berbasis teknologi dan diskusi tentang strategi pelaksanaan pembelajaran berbasis teknologi tepat guna melalui konsep ethnoscience. Selama kegiatan pelatihan, peserta dengan serius menyimak materi yang diberikan oleh narasumber/ pemateri. Pada akhir penyampaian materi, dilakukan diskusi yang konstruktif untuk mengungkap potensi dan kemampuan guru dalam menerapkan pengalaman dan pengetahuannya melalui alat teknologi tepat guna berbasis ethnoscience.

\section{b). Pelatihan dan pendampingan sesi II}

Pada kegiatan pelatihan dan pendampingan sesi II, dilakukan gelar aksi dari peserta. Kegiatan ini bersifat diskusi dan gelar pendapat dari peserta untuk membuat alat teknologi tepat guna berbasis ethnoscience yang dapat diterapkan dalam pembelajaran. Dari beberapa pendapat dan ide dari peserta selanjutnya direkapitulasi oleh tim untuk dilakukan kajian lanjutan. Kajian lanjutan ini dilakukan untuk mengkondisikan peserta dan menfasilitasi peserta untuk dapat membuat secara langsung alat teknologi tepat guna berbasis ethnoscience. Tim yang bertindak sebagai observer dan monitoring dari mitra melakukan pendampingan terhadap proses praktek oleh peserta.

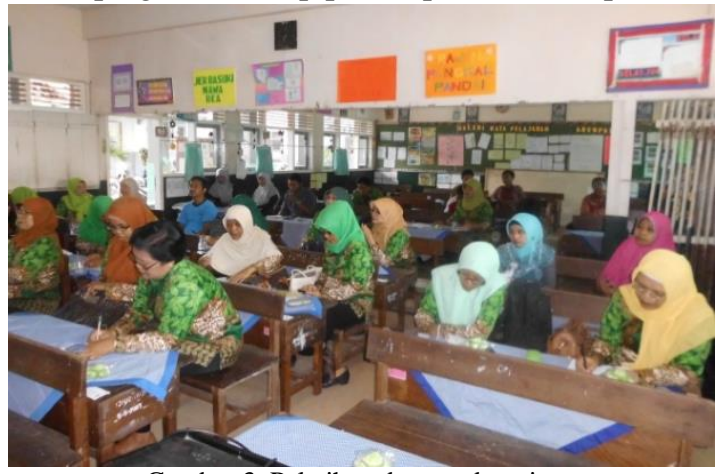

Gambar 3. Pelatihan dan pendampingan

Dari hasil pelatihan dan gagasan melalui praktek yang dilakukan peserta, kemudian dikaji bersama tim dan dilakukan pendampingan untuk direalisasikan dengan memberikan fasilitas pada peserta untuk membuat alat teknologi tepat guna.

Tim observer dan mitra melakukan diskusi dan pendampingan agar kesulitan yang dialami peserta akan dapat diatasi. Tahapan yang dilakukan antara lain; desain gambar alat yang diharapkan, menentukan alat dan bahan yang dibutuhkan, proses pembuatan alat hingga penggunaan alat sebagai media pembelajaran. 


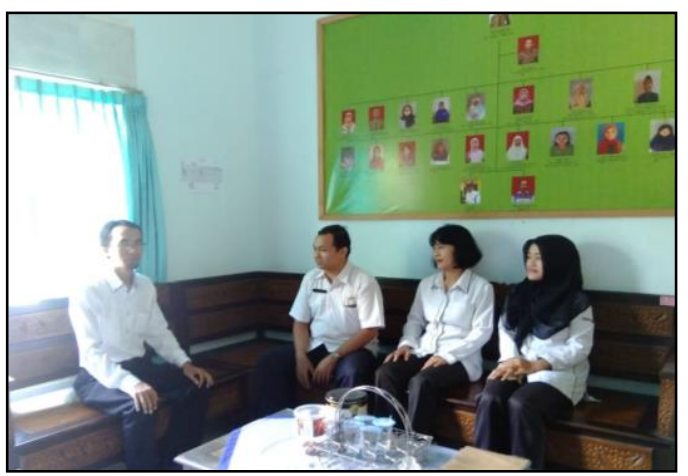

Gambar 4. Proses pendampingan dari Tim

Sedangkan skema yang diterapkan dari proses pendampingan pada mitra adalah

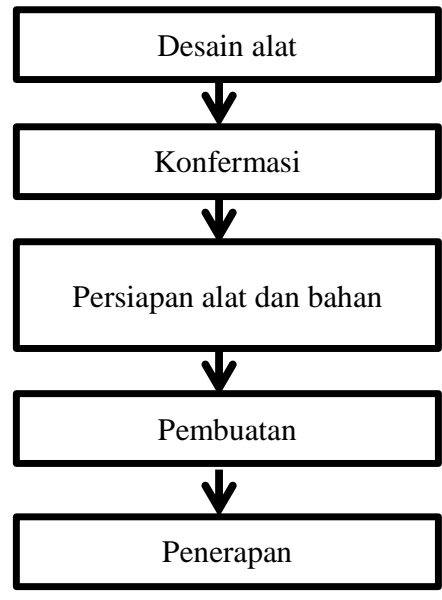

Gambar 5. Skema pendampingan

Pada tahapan desain alat, peserta menggambar model alat teknologi tepat guna pada selembar kertas yang disertai dengan alat dan bahan yang dibutuhkan. Peserta juga menentukan tujuan dan target yang akan dicapai peserta melalui alat yang dibuat. Dari beberapa desain dan model yang digambar peserta, dipilih beberapa model untuk dikonfermasi bersama tim yang selanjutnya akan ditindak lanjuti .

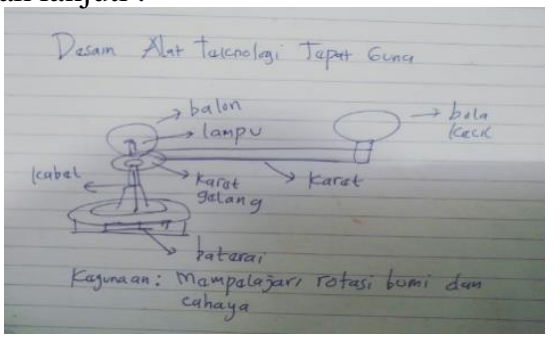

Gambar 6. Desain alat teknologi tepat guna karya peserta Desain yang telah terkonfermasi selanjutnya akan diberikan fasilitas oleh tim untuk kelengkapan alat dan bahan yang dibutuhkan serta pendampingan untuk proses pembuatan hingga selesai.
Tahapan selanjutnya adalah dengan menerapkan fungsi alat yang dihasilkan dalam pembelajaran.

\section{3) Evaluasi}

Tahap evaluasi adalah tahapan yang dilakukan untuk mengetahui hasil yang dapat dicapai selama proses kegiatan pengabdian dengan memperhatikan perkembangan dan peningkatan pengetahuan dan pemahaman mitra mengenai. Untuk mengetahui perubahan pengetahuan dan pemahaman mitra mengenai proses kegiatan dan penggunaan alat teknologi tepat guna berbasis ethnoscience, maka diberikan angket dan wawancara. Indikator angket dan wawancara antara lain; perubahan pemahaman mitra, peningkatan dan penambahan pengetahuan mitra dan kesiapan mitra dalam menerapkan materi yang telah diberikan oleh tim dalam kegiatan pembelajaran.

Hasil angket dan observasi dapat disajikan sebagai berikut:

I.

II.

Kedalaman dan pemahaman materi
\begin{tabular}{|c|c|c|c|}
\hline $\begin{array}{c}\text { Sangat } \\
\text { paham }\end{array}$ & Paham & $\begin{array}{c}\text { Cukup } \\
\text { paham }\end{array}$ & $\begin{array}{c}\text { Tidak } \\
\text { paham }\end{array}$ \\
\hline $20 \%$ & $68 \%$ & $10 \%$ & $2 \%$ \\
\hline
\end{tabular}

\begin{tabular}{|c|c|c|c|}
\hline Sajian materi pelatihan dan pendampingan \\
\begin{tabular}{|c|c|c|}
\hline Sangat \\
menarik
\end{tabular} & Menarik & $\begin{array}{c}\text { Cukup } \\
\text { menarik }\end{array}$ & $\begin{array}{c}\text { Tidak } \\
\text { menarik }\end{array}$ \\
\hline $70 \%$ & $20 \%$ & $10 \%$ & 0 \\
\hline
\end{tabular}

III.

Nilai kemanfaatan materi

\begin{tabular}{|c|c|c|c|}
\hline $\begin{array}{c}\text { Sangat } \\
\text { manfaat }\end{array}$ & manfaat & $\begin{array}{c}\text { Cukup } \\
\text { manfaat }\end{array}$ & $\begin{array}{c}\text { Tidak } \\
\text { manfaat }\end{array}$ \\
\hline $82 \%$ & $12 \%$ & $6 \%$ & $0 \%$ \\
\hline
\end{tabular}

IV

Perubahan Pemahaman dan Pengetahuan

V.

\begin{tabular}{|c|c|c|}
\hline Ada & Cukup & Tidak ada \\
\hline $72 \%$ & $20 \%$ & $8 \%$ \\
\hline
\end{tabular}

Target Penerapan selanjutnya

\begin{tabular}{|c|c|c|}
\hline Perlu & Cukup & Tidak Perlu \\
\hline $80 \% \%$ & $15 \%$ & $5 \%$ \\
\hline
\end{tabular}

Berdasarkan sajian tabel hasil analisa dan evaluasi angket, wawancara dan observasi pada mitra dapat diketahui bahwa mitra sangat antausias dan mendapatkan tambahan banyak pengetahuan dan pemahaman tentang pentingnya alat teknologi tepat guna berbasis ethnoscience yang langsung bisa diterapkan dalam pembelajaran sehingga siswa akan mampu menerima materi secara kontekstual dan sesuai dengan lingkungan yang ada sebagai sumber belajar. Pada kegiatan ini juga diberikan pantauan dan pendampingan pada mitra jika akan menggunakan media dan desain ini untuk penelitian tindakan kelas (PTK) atau karya tulis yang lain. 


\section{KESIMPULAN}

Melalui kegiatan pelatihan dan pendampingan oleh tim pada mitra yang merupakan Kelompok Kerja Guru (KKG) Gugus Karangrejo sebagai salah satu wadah kelompok guru diperoleh banyak perubahan, mulai dari perubahan pemahaman dan pengetahuan tentang penerapan ethnoscience yang dapat diterapkan melalui penggunaan alat teknologi tepat guna. Alat ini dihasilkan oleh guru melalui pelatihan dan pendampingan oleh tim sebagai pemateri, pendamping dan penilai serta memberikan konfermasi mengenai metode dan proses kerja yang tepat sehingga dapat digunakan dalam pembelajaran secara efektif dan bermanfaat. Dari hasil wawancara dan observasi diperoleh bahwa penerapan ethnoscience dalam proses pembelajaran sangat bermanfaat dalam mengantarkan pemahaman siswa pada teknologi yang dilakukan secara langsung melalui alat teknologi tepat guna bahkan meningkatkan pemahaman dan pengetahuan mitra sehingga memberikan keyakinan untuk menerapkan lebih lanjut.

\section{UCAPAN TERIMA KASIH}

Dengan terselesaikannya dari proses hingga akhir kegiatan pengabdian mandiri kepada masyarakat, tim mengucapkan terima kasih yang tak terhingga pada Lembaga Penelitian dan Pengabdian Masyarakat (PPPM) Politeknik Negeri Jember dan Kelompok Kerja Guru (KKG) Gugus Karangrejo Kecamatan Sumbersari yang telah mendukung dan memberikan ide serta gagasan dalam proses pelaksanaan hingg selesai.

\section{DAFTAR PUSTAKA}

[1] Andarwati, 2018. Pengaruh Pelatihan dan Penerapan Teknologi Tepat Guna (TTG) Terhadap Keberdayaan Pengrajin Batik Tulis Ramah Lingkungan. BRILIANT: Jurnal Riset dan Konseptual. 3 (3): 280-286

[2] BPS, 2016. Kajian Indikator Lintas Sektor: Potret Awal Tujuam p Berkelanjutan (Sustainable Development Goals) di Indonesia. Jakarta: Badan Pusat Statistik.

[3] Joseph, M.R, 2010. Ethnoscience and Problems of Method in The Social Scientific Study of Religion. Oxford journals. 39 (3): 241-249.

[4] Kemdikbud, 2015. Rencana Strategis Kementerian Pendidikan dan Kebudayaan Nasional tahun 2014-2019. Jakarta:Kemdikbud.

[5] Nugroho, 2017. Tujuan Pembangunan Berkelanjutan/ SDGs: Memikirkan Mekanisme Pendanaan. Disampaikan pada presentasi Deputi Kepala Staf Kepresidenan Bidang Kajian dan Pengelolaan Isu-isu Sosial, Budaya, dan Ekologi Strategis di Jakarta, 14 November 2017 